\title{
Pollak, Michael
}

1988 Les homosexuels et le SIDA: sociologie d'une épidémie. Paris, A. M. Métaili.

De igual modo que "EI SIDA $y$ sus metaforas" constituye una obra "inevitable" en la trayectoria profesional de Susan Sontag, Les Homosexuels et le SIDA: sociologie d'une épidémie, también lo es para Michael pollak,

Arxiu d'Etnografia de Catalunya, $n^{\circ} 7,1989,259-260$

ISSN: 0212-0372. EISSN: 2014-3885

http://antropologia.urv.cat/revistarxiu 
austriaco afincado en Francia, autor de un inmejorable -y ya clásico- artículo sobre el ghetto homosexual ( $L$ 'homosexualité masculine ou le bonheur dans le ghet to?").

La obra se divide en dos partes, compuestas, cada una, de tres capitulos, a los que hay que añadir unos anexos estadísticos. En la primera parte, elaborada a partir de encuestas pasadas a los lectores de Gai Pied Hebdo (la revista "gay" más leida y prestigiosa de Francia) 108 años 1985, 1986 y 1987 , se analizan algunas de las consecuencias que el SIDA ha tenido en el universo "gay", en especial en lo referente a la "re-programacion" de los deseos sexuales a partir del "sexo seguro". Si bien esta parte del libro no es novedosa (en particular para los que conocen los trabajos anteriores del autor), no tiene desperdicio el capitulo tres, en el que se detallan con habilidad los caracteres particulares de la relación médico-enfermo en el SIDA basándose sobre todo en relatos autobiográficos de enfermos.

Junto al capitulo tercero, la segunda parte del libro constituye 10 más novedoso del conjunto. En ella se analiza el papel de los mass-media como difusores del saber médico, y los intentos de politización de la enfermedad acontecidos en diversos paises, haciendo particular referencia al intento de neofascismo francs de asociar la enfermedad al desorden social y a la emigración. También detalla pollak el proceso de construcción del grupo de riesgo homosexual, que se elabora no sólo a partir de la noción de "riesgo médico", sino también (y fundamentalmente), mediante la noción de "riesgo social".

Finalmente el autor destaca en sus conclusiones la particularidad del fenómeno SIDA, y lo que le diferencia de otros procesos históricos similares; a saber: la preponderancia de la ciencia y de 108 medios de comunicación de masas, el fenómeno asociativo (ayuda mutua) y la coordinación internacional en la lucha contra la enfermedad.

La calidad de este libro 10 hace imprescindible en la biblioteca de cualquiera que pretenda tener una idea acertada de lo que ha sucedido y sucede en el universo homosexual como consecuencia del SIDA; sin embargo, se hecha en falta una prospección de futuro: no se tiene en cuenta el proceso de desinstitucionalizacin que hoy por hoy caracteriza al universo homosexual, ni tampoco se plantea la posible disolución de la cultura gay (o al menos su transformacin radical) como consecuencia de las restricciones impuestas por el SIDA.

En cualquier caso esperemos que para leer este buen libro en castellano ( $y$ a diferencia de 10 sucedido con Sexualités Occidentales) no haga falta esperar geis años.

Arxiu d'Etnografia de Catalunya, $n^{\circ} 7,1989,259-260$ ISSN: 0212-0372. EISSN: $2014-3885$
http://antropologia.urv.cat/revistarxiu

Oscar Guasch Andreu

Area d' Antropologia Social Tarragona 